\title{
A STUDY ON GENERATION OF SCOUR DUE TO STREAMS AROUND LARGE-SCALE GROINS UNDER TIDAL EFFECT
}

\author{
Takeshi ITO ${ }^{1}$ and Akihiro TOMINAGA² \\ ${ }^{1}$ Member of JSCE, River \& Water Resources Division, Chubu Office, CTI Engineering Co., Ltd. \\ (Nishiki 1-5-13, Naka-ku, Nagoya 460-0003, Japan) \\ E-mail: ito@ctie.co.jp \\ ${ }^{2}$ Member of JSCE, Professor, Department of Social Technology, Graduate School, Nagoya Institute of Technology \\ (Gokiso, Showa-ku, Nagoya 466-8555, Japan) \\ E-mail: tominaga.akihiro@nitech.ac.jp
}

\begin{abstract}
In the downstream tidal basin of the Kiso River, large-scale groins about $200 \mathrm{~m}$ long were constructed and a different river environment with pools and creeks was created by scouring, sedimentation, and foresting in intermediate areas of the groins. The scouring zone downstream of the large-scale groins played an important role in creating and maintaining an embayment water zone. In this study, we examined the scours that formed behind the large-scale groins in the Kiso River by field observations using acoustic Doppler current profiler (ADCP) and other observation equipment set downstream of the groins. The mechanism of creating downstream scour was then investigated by 2-D and 3-D numerical analyses in considering the effects of groins' lengths on the scouring. As a result, we found that offshore-heading streams occurred behind the groins during ebb tide and flood event, which may have caused the scouring downstream of the groins.
\end{abstract}

Key Words : Kiso river, large-scale groins, field observation, tidal flow, three-dimensional flow, 2D, 3D-numerical model

\section{PREFACE}

In the downstream part of the Kiso River, there are many Krippen groins mainly installed around the separation levee part of the Kiso River and Nagara River. These Krippen groins were installed mainly to fix low water channels or maintain- navigation channels ${ }^{1)}$. In recent years, attention has been paid to the fact that diverse river environments at the water's edge are formed by the complex streams created around the groins, changes in the riverbed, and vegetation ${ }^{2)}$. A series of embayments are formed between the Krippen groins, fostering multiplex ecosystems and creating a good river environment ${ }^{3), 4), 5)}$. The Krippen groins have the following characteristics: the length $L$ of each groin is rather long when compared with the river width $B$, with $L / B$ reaching around 0.3 to 0.5 . A compound channel is formed with a main channel created by the riverbed degradation in the non-groin areas, and the groin areas reside on the intermediate level plain (Refer to Fig.1).

Furthermore, the downstream part of the Kiso
River is in the tidal zone, and is subjected to the tidal level difference up to $2.5 \mathrm{~m}$. Thus, the groins are submerged during high tide. The groins with such characteristics have scoured areas in their downstream side, resulting in dead water zones being maintained for a long time. It is thought that the existence of scours in the downstream areas of the groins, which are uncommon in general groins, takes an important role in forming and maintaining the embayment water areas. Thus, understanding the scouring in the downstream area of Krippen groins and the processes of forming embayment water zones is an important subject in river channel management.

There have been advanced studies with experiments or numerical calculations on sedimentation between groins, making predictions on such phenomena as local scouring at the groin tip, the effects of groin resistance on the surge of water level, and on the velocity reduction in the vicinity of the riverbank possible to some degree ${ }^{6), 7), 8)}$. In recent years, experimental studies under various conditions have been carried out, including complex shapes, ar- 


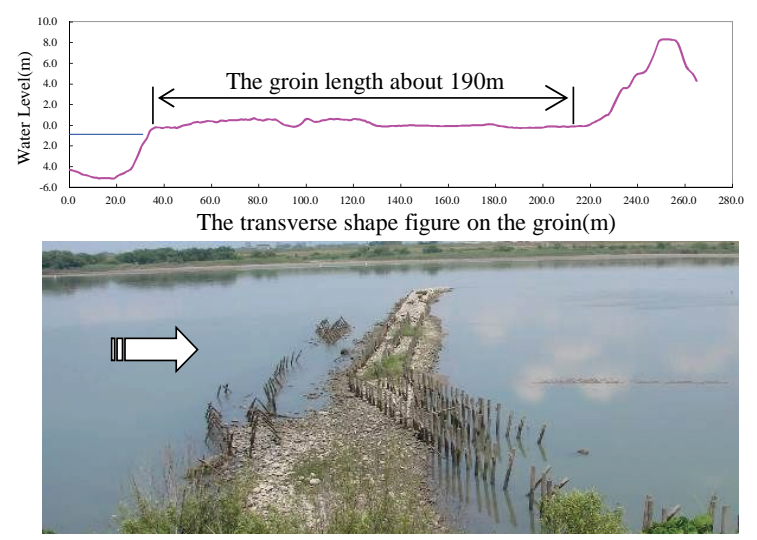

Fig.1 Krippen groin in the lower reach of Kiso River.

rangements focusing on aspect ratio, permeability of groins, and usage of mixed sand, etc. ${ }^{9), 10), 11)}$. In the case of experimental channels, however, due to the change in the water level and the limitation in scale, it is difficult to conduct experiments on large-scale groins installed in channels with high width-depth ratio or those installed in the areas influenced by tide.

This research was conducted on a large-scale groin installed in the tidal zone of the Kiso River with the aim of revealing generation mechanisms of the scours noticed downstream of the groin. In addition to the observations done in the previous study 12), site observations using ADCP were carried out to detect tide-caused changes in the flow structure along the longitudinal direction behind the groin, and $2 \mathrm{D}$ and $3 \mathrm{D}$ numerical simulations were also performed on the flow related to the scouring downstream of the groin.

\section{OBSERVATIONS ON FLOWS AROUND GROINS IN THE KISO RIVER}

(1) Observations on flows around Krippen groins

In the area of the Kiso River where Krippen groins were installed, aerial laser survey and swath echo sounding were carried out. A groin at the $15.6 \mathrm{k}$ point residing in the zone where the results of above surveys had been sorted out was selected as the observation target of this study. The observations were performed with survey equipment deployed downstream of the groin targeting the periods which included spring tides from 2012 to 2015 as shown in Table 1. During the survey in 2012, electromagnetic current meters were arranged widely between groins to observe the horizontal flows between the groins. Noting scours existing downstream of the target groin, the surveys in 2013 and 2015 deployed observation equipment focusing on the scour areas. During the survey in 2013, three units of ADCP and
Table 1 Periods of the flow observation around the groin and equipment used.

\begin{tabular}{|c|l|l|}
\hline \multicolumn{1}{|c|}{ Period } & \multicolumn{1}{|c|}{ Equipment } & \multicolumn{1}{c|}{ Remarks } \\
\hline 2012.7.3-7.6 & INFINITY-EM 9 units & $\begin{array}{l}\text { normal condition, } \\
\text { spring tide }\end{array}$ \\
\hline $2013.7 .1-7.11$ & $\begin{array}{l}\text { ADCP(WHS1200) } 3 \text { units } \\
\text { H-ADCP(WHH300) } 3 \text { units }\end{array}$ & $\begin{array}{l}\text { flood, } \\
\text { spring tide }\end{array}$ \\
\hline 2015.5.29-6.5 & $\begin{array}{l}\text { ADCP(WHS1200) } 3 \text { units } \\
\text { ADCP(SV20) }\end{array}$ & $\begin{array}{l}\text { normal condition, } \\
\text { spring tide }\end{array}$ \\
\hline
\end{tabular}

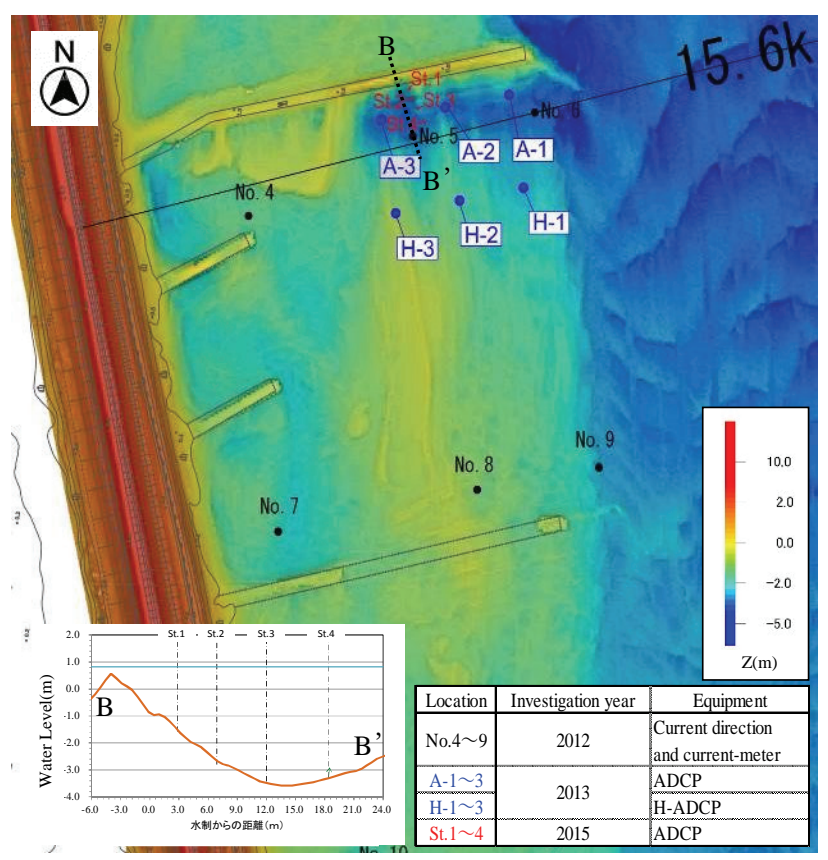

Fig.2 Riverbed level and arrangement of survey equipments.

three horizontal acoustic doppler current profiler (H-ADCP) aligned in parallel were deployed along the transverse direction to observe the three-dimensional flow structures in the downstream side of the groin. In the survey of 2013, a small-scale flood occurred during the survey period, enabling observations of rare and valuable data. The survey in 2015 performed observations deploying four units of ADCP placed along the longitudinal direction in order to detect structures of vortexes with an axis of the transverse direction in the downstream side of the groin. Locations of the equipment are shown in Fig.2.

\section{(2) Occurrence of offshore flows during ebb tide}

Water levels, flow directions, and velocity as results from the observations carried out during normal conditions in 2012 and 2015 are shown in Fig.3 and Fig.4. In the 2012 survey, observation equipment was set up $50 \mathrm{~cm}$ above the riverbed at a downstream point (No. 6) in the viciity of the groin's tip to perform the observation at 10-minute intervals. Figure 3 shows data of the observed northward and eastward velocity, and 30-minute moving average. For the survey in 2015, northward and eastward velocities 
were observed at 2-minute intervals at a point $50 \mathrm{~cm}$ above the ADCP of St. 2 close to the riverbed in the downstream side of the groin at the middle section. Figure 4 shows the observed values and 30-minute moving average. From these figures, periodical changes in velocity linked with the tide are noticed around the bottom surface in the downstream side of the groin, observing northward velocity (downstream direction) of -20 to $-40 \mathrm{~cm} / \mathrm{s}$ and eastward velocity (offshore direction) of 20 to $30 \mathrm{~cm} / \mathrm{s}$. Downstream velocities (in northward velocity) are high in the vicinity of the groin's tip, while they are considerably low at the middle of the groin. Contrarily, transverse velocities (in eastward velocity) appear to be high not only at the groin's tip but also at its middle. From these, it is confirmed that, in the downstream side of the groin under the effect of tide, flows that transport riverbed material to the offshore-downstream side are in an active state during the period of overflowing around the groin, even during normal conditions.

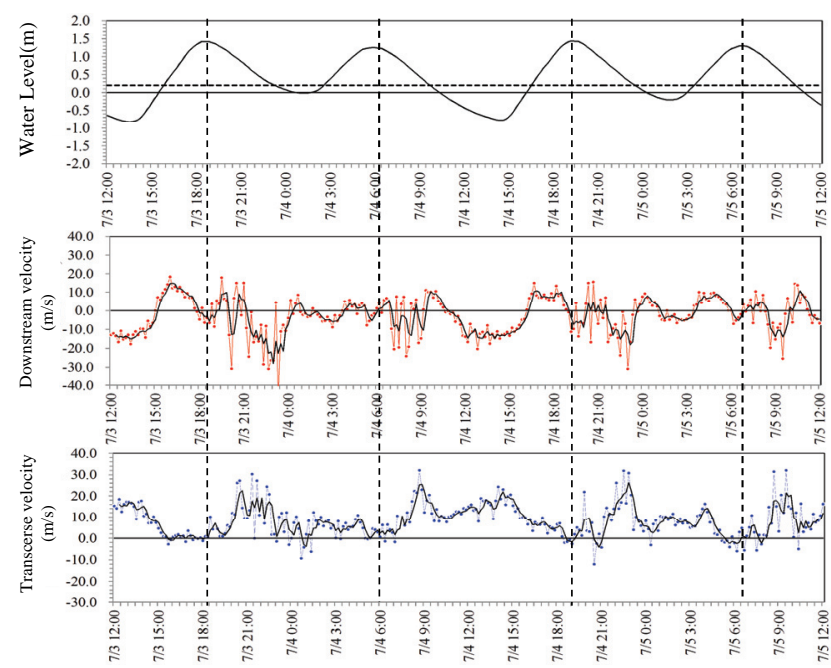

Fig.3 Flow direction/ velocity downstream of the groin during normal conditions (2012, No.6).
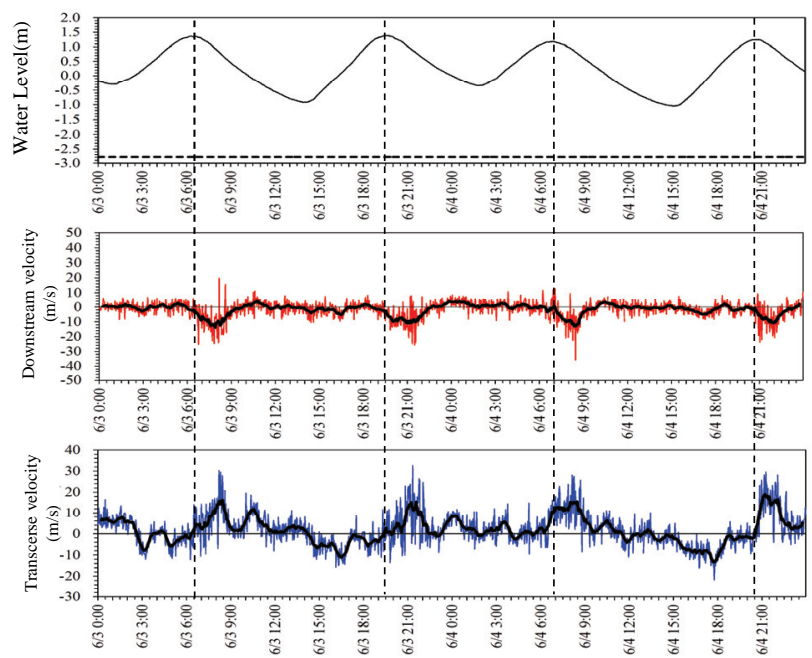

Fig.4 Flow direction/velocity downstream of the groin during normal conditions (2015, St.2).
(3) Occurrence of three-dimensional flows in the downstream side of the groin

As a result of the observations during the flood in 2013, correlations of the flow direction and velocity in the bottom layer (average from $0.0 \mathrm{~m}$ to $0.5 \mathrm{~m}$ above ADCP) and in the surface layer (average from $2.0 \mathrm{~m}$ to $2.5 \mathrm{~m}$ above ADCP) at A-2 point are shown in Fig.5. The figure shows that, while the northward velocities demonstrate apparent downstream (southward) flows in the surface layer, they show slight upstream (northward) flows in the bottom layer, indicating a difference in the flow direction between the surface layer and the bottom layer. For the eastward velocity, whereas remarkable offshore (eastward) flows occur in the bottom layer, no eastward flow occurs in the surface layer. From these results, it is inferred that, in the downstream side of the groin during flood, while overflows around the groin continue flowing downstream in the surface layer, they scarcely influence the bottom layer where vortexes with an axis of the transverse direction (transverse vortexes) appear to have been created. On the other hand, the occurrence of offshore (eastward) flows in the bottom layer, similar to normal conditions, means that flows transporting the riverbed material to the offshore side are also in an active state during floods.

To examine flows behind the groin with the tidal effect in normal condition, ADCP was set downstream of the groin in the 2015 survey.

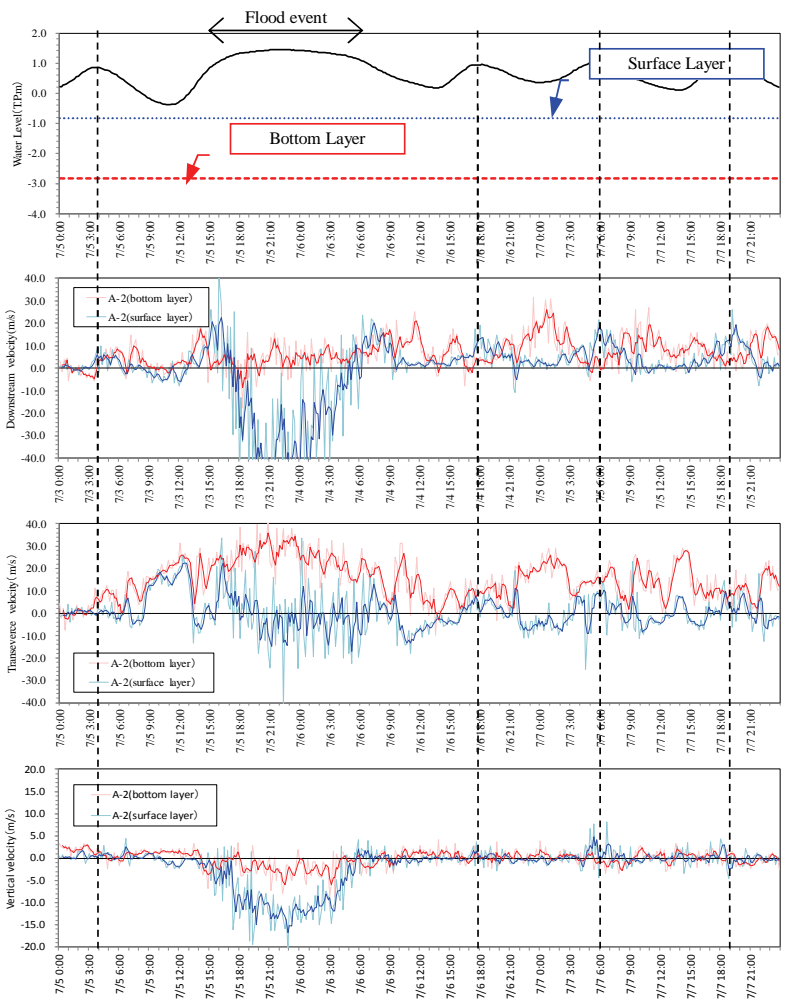

Fig.5 Flow direction/velocity downstream of the groin in flood (2013, A-2). 

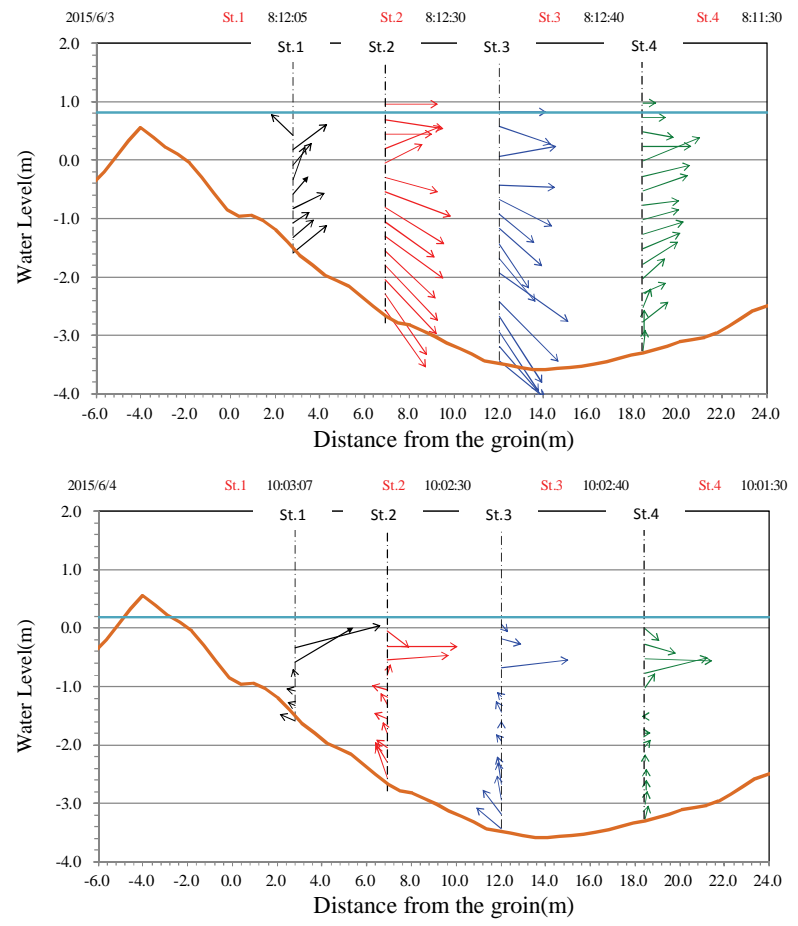

Fig.6 Forming transverse vortexes downstream of the groin.

From the observation results, velocity vectors showing the side views of the downstream velocity and vertical velocity during ebb tide are shown in Fig.6. As seen in the figure, when the water level is high enough to reach the overflow state in front of the groin, downstream flows are recognized from the surface layer to the bottom layer. This is a characteristic that is different from the case of overflow caused by flooding. On the other hand, when the water level has gone down to such a level that the water overflow cannot occur on some high spots of the groin, downstream flows are noticed in the surface layer, while upstream flows are seen in the bottom layer, indicating that transverse vortexes are formed. The transverse velocities shown in Fig.6 and Fig.4 demonstrate that, during an ebb tide with a high water level, overflows around the groin directly affect the riverbed, and the offshore flows transport sediment toward the main channel. Furthermore, during an ebb tide with a low water level, transverse vortexes are created downstream of the groin, and the offshore flows at the riverbed zone transport sediment toward the main channel. Thus, it is considered that, with these actions, scours are created and maintained downstream of the groin.

\section{(4) Relationship between tide and reflection in- tensity}

In observations using ADCP, the flow direction and velocity are obtained from the reflection intensity of soundwaves. This reflection intensity is considered to have a relationship with the amount of
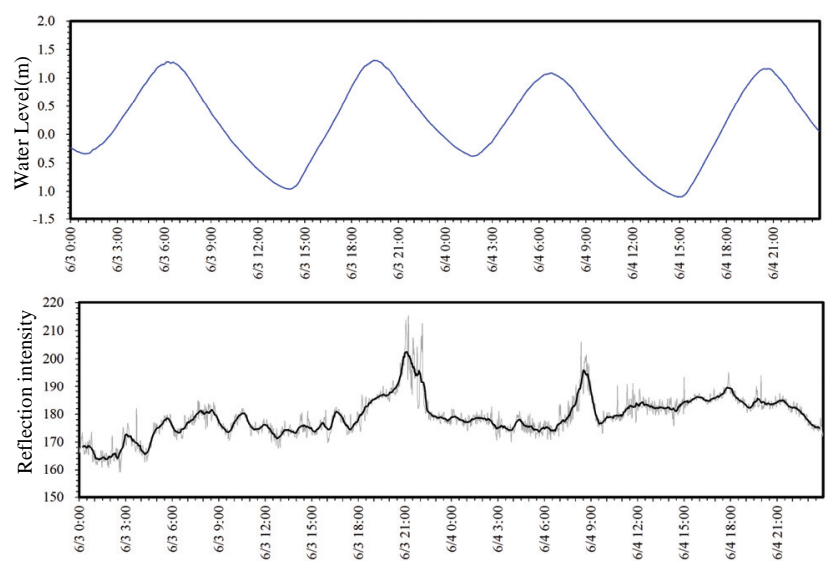

Fig.7 Changes in reflection intensities in normal condition (2015. St.2).

sand suspended in the water. Thus, looking at changes in the reflection intensities enables us to speculate as to whether sediment is moving in/around the scours in the downstream side of the groin under tidal effect. From the survey in 2015, the relationship between changes in tide levels and reflection intensities in normal conditions are shown in Fig.7. The result demonstrates a phenomenon in which reflection intensities and the amount of suspended sand increase while tide shifts from high tide to ebb tide. An increase in the reflection intensity was also noticed in the results from the observation during the flood in 2013. From these events, it is inferred that the overflows around the groin during either flood or ebb tide act on the riverbed of scours in the downstream side of the groin, and the entrained sediment is transported toward the main channel by the offshore flow. It is further inferred that much sediment moves offshore during flooding, and during normal conditions as well; sediment always moves offshore with the effect of tide shifting from high tide to ebb tide, maintaining the scours in the downstream side of the groin.

\section{SIMULATION OF FLOWS AROUND THE GROIN}

\section{(1) Influence of tides according to the flat two-dimensional model}

A generalized curvilinear coordinate 2-D model was applied in order to reproduce the flows downstream the groin. The calculations were performed in the modeled channel with relatively long groins as in the Kiso River Krippen Groin for which field observation was executed. This 2-D analysis was carried out using the Nays2D Solver for the river numerical analysis common platform iRIC.

In a channel of approximately $400 \mathrm{~m}$ width, a 
groin with a length of approximately $200 \mathrm{~m}$, of the same scale as the actual site, was installed, and modeling was performed under the conditions existing in the scour downstream from the groin. Also, calculations were performed under conditions in which flooding, overflow, and exposure were repeated as influenced by the tides. The model creation conditions are shown in Table 2, and tide fluctuations are given. The results of simulations at the time of tide ebbing from high tide are shown in Fig.8. From the velocity vectors in the scour downstream of the groins, it can be confirmed that offshore-heading flows occur during ebb tide and the flows observed in the local survey are reproduced in the numerical simulation.

It is surmised that the offshore-heading flows occur due to the influence of water-level differences between the main channel and the region between groins during the ebb tide, and that the water stagnating between groins is diverted to the main channel.

The water-level differences in the scour area downstream of the groin and variations in the downstream and transverse velocities are shown in Fig.9. From this figure, we can see that, when the water level exceeds the height of the groin $(0.2 \mathrm{~m})$, the velocity in the downstream direction overflowing the groin increases. When there is no overflow during ebb tide, there is virtually no downstream velocity. The transverse velocity indicates offshore-heading flows for almost all period, and the peak velocity occurs during ebb tide. The offshore-heading flow is recognized during periods in which water level is lower than the groin height and overflows do not occur. This is thought to occur because flows that water stagnating between the groins return to the main channel is concentrated just behind the groin.

In the region between large-scale groins on the flood plain, even a 2-D simulation was able to reproduce the observed characteristics to a certain extent. In the simulation, modeling was performed with reference to the groin channel shape and groin transverse-elevation targeted in the field observation. However, the transverse velocity tends to demonstrate values lower than those of the field observation results. The cause is attributed to the differences between the discharge applied to the model and that at the observation points. The discharge at the time of observation is grasped from the actual discharge at Kisogawa-ozeki weir in the area $24 \mathrm{k}$ from the river mouth; however, discharge at the observation point is deemed to become larger than the discharge released from the weir due to the influence of ebb tide.
It is also surmised that neglecting the topography between the groins and the effect of 3-D flows caused the disparity with the local observations.

Table 2 Model creation conditions.

\begin{tabular}{|c|l|}
\hline $\begin{array}{c}\text { Vertical } \\
\text { mesh }\end{array}$ & $\begin{array}{l}\text { No. of mesh 265 } \\
\text { Mesh size } 6.0 \mathrm{~m}\end{array}$ \\
\hline $\begin{array}{c}\text { Horizontal } \\
\text { mesh }\end{array}$ & $\begin{array}{l}\text { No. of mesh 66 } \\
\text { Mesh size Approximately 6.0 m } \\
\text { Groin length 196 m, low channel width } \\
196 \mathrm{~m}\end{array}$ \\
\hline $\begin{array}{c}\text { Ground } \\
\text { elevation }\end{array}$ & $\begin{array}{l}\text { Low channel site }-4.0 \mathrm{~m} \text {, groin installa- } \\
\text { tion section-1.0 m } \\
\text { Groin site } 0.2 \mathrm{~m}, \\
\text { (set from site situation) }\end{array}$ \\
\hline $\begin{array}{c}\text { Roughness } \\
\text { coefficient }\end{array}$ & $\begin{array}{l}\text { Low water channel:0.025, Between } \\
\text { groins:0.035 }\end{array}$ \\
\hline $\begin{array}{c}\text { Downstream } \\
\text { toe water level }\end{array}$ & Assumes tides(Fig.8) \\
\hline Flow rate & $400 \mathrm{~m}^{3} / \mathrm{s}$ quantification \\
\hline
\end{tabular}

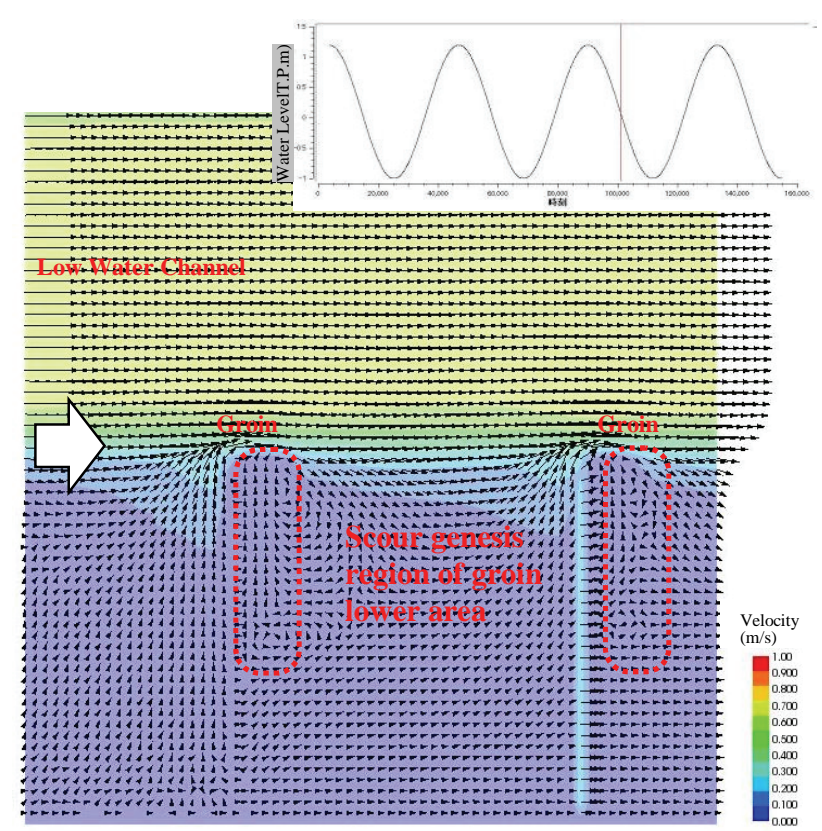

Fig.8 Analysis results around the large-scale groin.

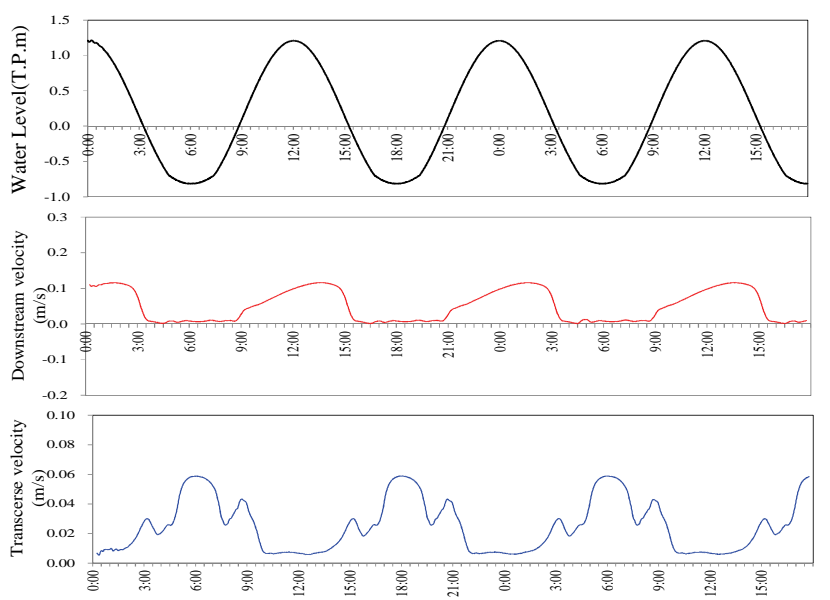

Fig.9 Water level/downstream direction velocity /transverse velocity. 
(2) Relationship between groin scale and offshore-heading flow velocity

In order to confirm whether the length of the groin affected the offshore-heading flows occurring downstream from the groin, we performed a plane 2-D analysis in changing the groin length from $12 \mathrm{~m}$ to $200 \mathrm{~m}$. Furthermore, to confirm the influence of the stagnation between the groins, the length $W$ between the groins was changed in accordance with the change in the groin length $L$, and an analysis was performed with the fixed aspect ratio of $A R(=L / W)$. As the calculation conditions, the groin length and groin interval were changed based on Table 2 . Furthermore, because the cross-sectional area of the river also changes by changing the groin length, the flow scale was changed to fix the discharge per unit area as shown in Table 3.

Figure 10 demonstrates changes in the transverse flow velocity downstream of the groin, based on the analysis results under the conditions shown in Table 3. In the figure, $L$ indicates the groin length. Furthermore, Fig.11 shows the relationship between the groin length and the transverse velocity. From this figure, we can see that the flow velocity downstream of the groin increases with an increase of the groin length. No significant differences were seen when fixing the aspect ratio and changing the interval between groins.

Table 3 Relationship between groin lengths, lengths between groins, and target flows.

\begin{tabular}{|c|c|c|c|c|c|}
\hline $\begin{array}{c}\text { groin length } \\
\mathrm{L}(\mathrm{m})\end{array}$ & $\begin{array}{l}\text { distance } \\
\text { between groins } \\
\mathrm{W}(\mathrm{m})\end{array}$ & $\operatorname{AR}(=L / W)$ & $\begin{array}{c}\text { cross-section } \\
\text { area of the river } \\
\mathrm{A}\left(\mathrm{m}^{2}\right)\end{array}$ & $\begin{array}{l}\text { flow rate } \\
\mathrm{Q}\left(\mathrm{m}^{3} / \mathrm{s}\right)\end{array}$ & $\mathrm{Q} / \mathrm{A}$ \\
\hline 200 & \multirow{7}{*}{200} & 1.00 & 1449.6 & 400 & \multirow{10}{*}{0.28} \\
\hline 150 & & 0.75 & 1598.1 & 441 & \\
\hline 100 & & 0.50 & 1746.6 & 482 & \\
\hline 50 & & 0.25 & 1895.1 & 523 & \\
\hline 30 & & 0.15 & 1954.5 & 539 & \\
\hline 20 & & 0.10 & 1984.2 & 547 & \\
\hline 12 & & 0.06 & 2007.9 & 554 & \\
\hline 150 & 150 & \multirow{3}{*}{1.00} & 1598.1 & 441 & \\
\hline 100 & 100 & & 1746.6 & 482 & \\
\hline 50 & 50 & & 1895.1 & 523 & \\
\hline
\end{tabular}

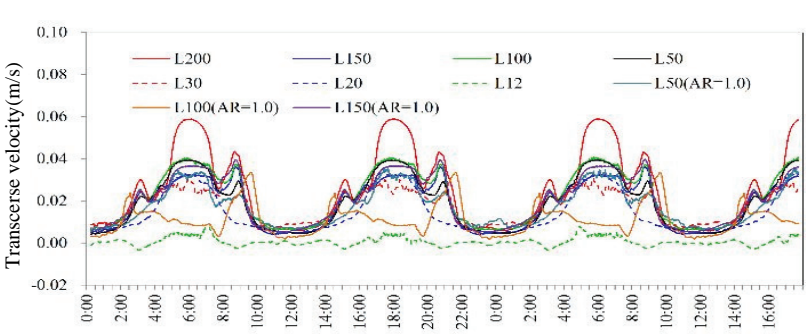

Fig.10 Analysis results of transverse velocity in relation to groin length.

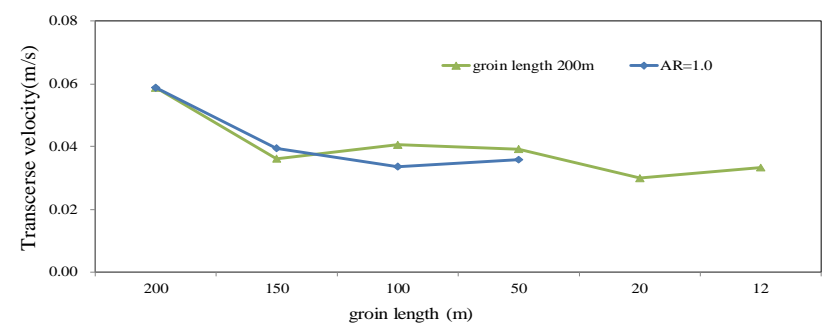

Fig.11 Changes in transverse velocity in relation to groin length.

\section{(3) Groin downstream 3-D flows using 3-D anal- ysis}

In the same way as in the 2-D analysis, a generalized curvilinear coordinate 3-D model was applied to the channel and groin model, and reproduction of the 3-D flows downstream of the groin was verified. For the 3-D analysis, an iRIC NaysCUBE was used and, for the turbulence model, a second-order non-linear $k-\varepsilon$ model $^{14)}$ was applied. For the model constants, the AHK model ${ }^{12),}{ }^{13)}$ was adopted. Calculation conditions involved the subdivision of the mesh size and 10 partition in the vertical direction for the plane 2-D model displayed in Table 2. Furthermore, the groins were modeled as obstacles and similar flows as observed at the time of floods in 2013 (approximately 2,500 $\mathrm{m}^{3} / \mathrm{s}$ ) were given as a steady condition.

The 3-D calculation results demonstrated the generation of an unsteady periodic large-scale vortex structure, regardless of the analysis under steady conditions. Figure 12 shows the stream line and the velocity contour when the large-scale vortex is generated. Based on this, it can be confirmed that in the scour region downstream of the groin, a transverse vortex occurred in the same way as in the site observations, and the flow is heading to the offshore direction as indicated by the stream line. It is recognized that this offshore-heading vortex is generated periodically. From these analysis results, it can be confirmed that the generation of the transverse-vortex downstream of the groin observed at the time of the flood can be expressed via 3-D numerical analysis.

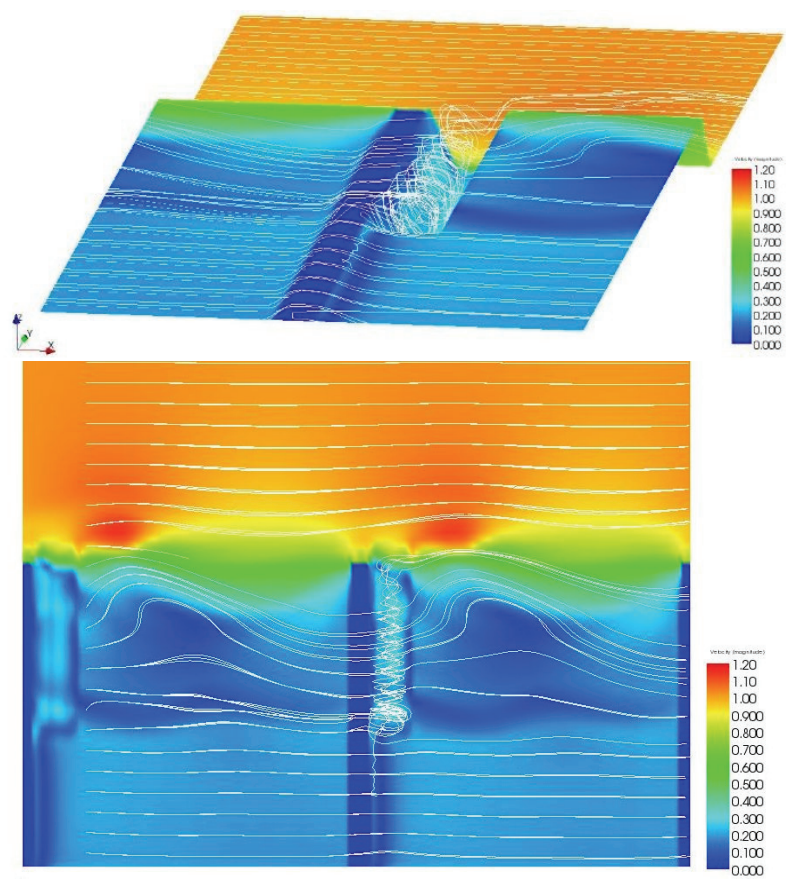

Fig.12 Generation of a transverse-vortex downstream of the groin by 3-D analysis. 


\section{DISCUSSION ON THE GENERATION PROCESS OF SCOURS DOWN- STREAM OF LARGE-SCALE GROINS}

In regard to the factors in which the scour occurred downstream of the large-scale groins, we performed an analysis after executing field observations and hydraulic analysis during floods. As a result, under normal conditions, downstream offshore-heading flows along the bottom occurred due to the tidal effects in the initial stages of ebb tide after high tide, and this worked to transport the sediment on the river bed. When the water level decreased furthermore, a transverse vortex occurred and this transported sediment entraining riverbed materials offshore. It is considered that, when flood occurs, due to the generation of the transverse vortex downstream of the groin and the generation of the offshore flows, sediment is transported offshore.

From these observations, it is thought that the scour is generated by the action of flows at the time of floods, and it is maintained by the action of tides during normal times.

\section{CONCLUSION}

In this study, the aim was to understand the scour generation mechanism occurring downstream of large-scale groins installed in tidal areas. The flow structures downstream of the groins were investigated through field observations including the flood season, and 2-D and 3-D numerical analyses.

From the results of the field observations, it was confirmed that transverse flows were generated on the bed of the scour region downstream of the groin.

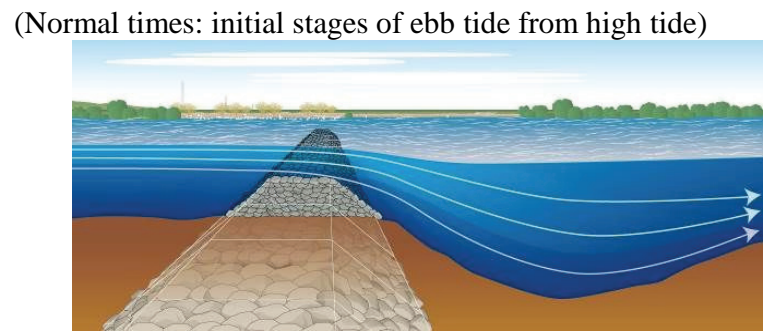

(At time of flood)

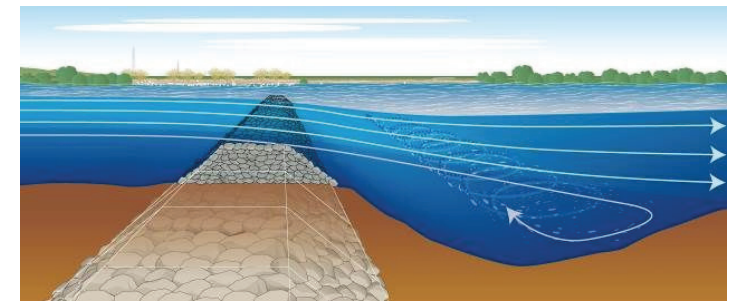

Fig.13 Image of flows downstream of the groin during normal times/flood times.
Furthermore, from the observations using ADCP at the time of flood, it was seen that a transverse vortex was formed downstream of the groin and this vortex headed offshore; thus, this was deemed a factor in generating scours downstream of the groin. It is also surmised that, during normal tide conditions, downstream offshore-heading flows are generated at the bottom downstream of the groins during ebb tide, and transverse vortexes are generated, which work to maintain the scours.

In the numerical analyses, it was confirmed that, through 2-D flow analysis, it was possible to reproduce offshore-heading flows generated downstream due to the influence of tide with a certain degree of precision. Furthermore, in the analysis modifying the groin length and aspect ratio, it was confirmed that the longer the groin length, the greater the offshore-heading velocity.

The 3-D analysis aimed at the area between groins showed that the formation of a transverse vortex with the offshore-heading flows can be reproduced during floods.

Moving forward, we need to clarify the generation of offshore-heading flows downstream of the groins, as well as the generation mechanism and generation conditions of the transverse vortex, by changing conditions such as the river scale and relative height of the main channel and the flood plain. There is also a need to investigate the conditions for installing the groin to encourage the formation of embayments and creeks.

ACKNOWLEDGMENT: While carrying out this study, the authors received valuable information from the Kiso River downstream river office of the Central Development Bureau, Ministry of Land, Infrastructure, Transport and Tourism. We would like to express our deepest gratitude here to all those who provided their support.

\section{REFERENCES}

1) Yamamoto, K.: Groins of Japan, Sankaido, 1996.

2) Fukuoka, S.: Flood Hydraulics and River Channel Design Methods, Morikita Publishing, 2005.

3) Kimura, I., Kitamura, T., Washimi, T., Takeda, M., Onitsuka, K., Sho, K. and Otsuka, Y.: Joint research concerning wand formation process and river environments in groin areas located in the Kiso River tidal zone, River Technology Thesis Collection, Vol. 8, pp. 356-370, 2002.

4) Shinoda, T., Mizutani, N., Matsuyama, Y. and Tsujimoto, T.: Observations on the wand formation process and waterside environment features as seen from the topographical history of Krippen groin, River Technology Thesis Collection, pp. 333-338, 2001

5) Tsubaki, R., Furuhata, H. and Tsujimoto, T.: Flow structure and wand topography transition of the Kiso River downstream areas during floods, including groin groups, Water Engineering Thesis Collection, Vol. 52, pp. 691-696, 2007. 
6) Kawaguchi, K., Okanobu, M. and Fukuoka, S.: Features of hydromechanics working in overflow-type groin groups, Water Engineering Thesis Collection, Vol. 4, pp. 1065-1070, 2000.

7) Chung, J. H. and Tominaga, A.: Flow structure of compound-section river channels with groins for flood channels, Water Engineering Thesis Collection, Vol. 53, pp. 913918, 2009.

8) Yonemura, K., Kimura, I. and Shimizu, Y.: Influence of the aspect ratio of non-overflow continuous groins on water depth and 3-D flow regimes, Water Engineering Thesis Collection, Vol. 58, pp. 673-678, 2014.

9) Matsumoto, D., Tominaga, A. and Ishikawa, M.: Transient influence on river bed fluctuation creation using overflow-type groin groups, Water Engineering Thesis Collection, Vol. 52, pp. 637-642, 2008.

10) Mizutani, H., Nakagawa, H., Kawaike, K., Baba, Y. and Zhang, H.: Studies concerning local scours and granularity changes around non-overflow/ non-transparent grounds, Water Engineering Thesis Collection, Vol. 55, pp. 829-834, 2011.
11) Hirakawa, R., Watanabe, K., Matsumoto, S. and Ohira, A.: Studies regarding flow structure downstream from single groin or continuous groin burbles, Practical Mechanics Thesis Collection, Vol. 15, pp. 565-572. 2012.

12) Ito, T. and Tominaga, A.: Observations concerning mechanism for generation of scours occurring downstream of large-scale groins, Water Engineering Thesis Collection, Vol. 59, pp. 1153-1158, 2015.

13) Kimura, I. and Hosoda, T.: A non-linear $k-\varepsilon$ model with realizability for prediction of flows around bluff bodies, International Journal for Numerical Methods in Fluids, Vol. 42, pp. 813-837, 2003.

14) Ali, M. S., Hosoda, T. and Kimura, I.: A non-linear $k-\varepsilon$ model to predict the spatial change of turbulent structures in large-scale vortices, Journal of Applied Mechanics, JSCE, Vol. 10, pp. 723-732, 2007.

(Received August 4, 2017) 